\title{
Multidimensional Health-Related Quality-of-Life Among Patients with Pulmonary Tuberculosis in Saudi Arabia
}

\author{
Ghofran Omar Dhelaimi ${ }^{1}$, Turki Suwaylim Alsaedi ${ }^{1}$, Muteb Omtairan Alharbi ${ }^{2}$, \\ Fahad Alkaraiem ${ }^{2}$, Abdulhameed Saleem Altarjami ${ }^{2}$, Ayman Ahmad Alkaraiem ${ }^{3}$, \\ Ergie Pepito Inocian ${ }^{4}$ \\ ${ }^{1}$ National Tuberculosis Program, Ministry of Health, Madinah, Saudi Arabia \\ ${ }^{2}$ Pilgrimage City Hospital, Ministry of Health, Madinah, Saudi Arabia \\ ${ }^{3}$ Applied Health Sciences, Taibah University, Madinah, Saudi Arabia \\ ${ }^{4}$ Nursing Department, King Khalid University Hospital, Riyadh, Saudi Arabia
}

Email address:

turki33r@gmail.com(T. S. Alsaedi)

To cite this article:

Ghofran Omar Dhelaimi, Turki Suwaylim Alsaedi, Muteb Omtairan Alharbi, Fahad Alkaraiem, Abdulhameed Saleem Altarjami, Ayman Ahmad Alkaraiem, Ergie Pepito Inocian. Multidimensional Health-Related Quality-of-Life Among Patients with Pulmonary Tuberculosis in Saudi Arabia. World Journal of Public Health. Vol. 3, No. 2, 2018, pp. 48-56. doi: 10.11648/j.wjph.20180302.13

Received: April 25, 2018; Accepted: May 16, 2018; Published: June 19, 2018

\begin{abstract}
This study aimed to explore the multi-dimensional health-related quality of life (HRQOL) among tuberculosis patients and examined its association between with their demographic profiles. A cross-sectional survey using the Functional Assessment of Chronic Illness Therapy-Tuberculosis (FACIT-TB) was carried out on a convenience sample of 87 tuberculosis patients at a large tertiary hospital operating the National TB Control Program (NTP) under the Ministry of Health, Western Region, Saudi Arabia. The overall HRQOL of the respondents is poor, whereas the different dimensions were rated as poor to moderate. The respondents' age, smoking status, duration of TB, experience of travelling outside KSA, and educational attainment exhibited significant association to some degree with some of the dimensions of HRQOL. Strategies to strengthen the treatment support could sustain acceptable levels of physical, social and emotional functioning among TB patients. The need to increase public awareness about tuberculosis is needed to ensure prompt healthcare seeking, early detection, adherence to remedy, and better prognosis.
\end{abstract}

Keywords: Quality of Life, Saudi Arabia, Tuberculosis

\section{Introduction}

Over the past decades, assessing the quality of life in different diseases has appeared to be a valuable research tool to improve clinical practice and better patient outcomes. Tuberculosis (TB), a disease caused by bacteria (Mycobacterium tuberculosis) most often affecting the lungs and transmitted airborne, is one of the top 10 leading causes of death worldwide despite its preventable and curable form. The World Health Organization (WHO) [1] estimated that in 2015, there were 10.4 million people contacted the tubercle bacilli wherein 1.8 million died from the disease. Despite significant investments in TB control over the years, TB remains an important public health problem in the KSA. TB control has been accorded a high priority within the health sector as it is a major public health problem [2]. Measuring the quality of life of TB patients provides an essential source of information to increase health awareness and to influence policy in the kingdom such as providing comprehensive care program to support people with transmissible disease. Thus, this study was conducted to assess the health-related quality of life (HRQOL) of patients with Tuberculosis in Saudi Arabia.

\section{Review of Related Literature}

Tuberculosis (TB) is a serious public health concern is one of the oldest infections affecting millions of individuals around the world. It remains one of the 10 leading causes of mortality, and affects all age groups [3]. In Saudi Arabia, approximately 64,345 TB cases were reported to the Ministry of Health during 1991-2010 [4]. TB has significant impact 
not only to the patient, but to the entire country. For example, TB can cost a country as much as $7 \%$ of its Gross Domestic Product [1]. Moreover, TB also impacts the patient's HRQOL and health status, which are very significant for patient care, the evaluation of preventive and treatment strategies, and also for health policy. Quality of life information are critical aspect in evaluating health economics [5]. Therefore, putting an end to the TB epidemic by 2030 has become one of the health targets of the World Health Organization's newly adopted Sustainable Development Goals [1].

The HRQOL is defined as "the individual's perception of their position in life considering the cultural context and value system in which they live and in relation to their goals, expectations, standards, concerns, and desires" [6]. This definition signifies the effect of diseases and related morbidities on daily activities and functioning of an individual. This definition reflects quality of life as a subjective evaluation that is contextualized within a specific cultural, societal, and environmental background. Despite the burden associated with TB, which is acknowledged for many years, systematic investigation of HRQOL is a much more recent development [7]. The challenges associated with conducting systematic evaluation of HRQOL among TB patients can be broken down to several factors. For instance, most of validated HRQOL measures are non-TB specific, which cannot provide reliable measure of HRQOL among this population group. Furthermore, choosing appropriate comparator populations is also a challenge, as well as the lack of normative data on health status for the general population in many TB endemic areas. Also, existing systematic evaluations were conducted among TB patients in specific groups, such as those with extrapulmonary TB, drugresistant disease, HIV co-infection, and latent TB infection (LTBI), or in children with TB, which make 'health status' summaries in TB more challenging [5]. However, the FACIT-TB was recently created, which is a disease-specific instrument designed to assess HRQOL in patients diagnosed with PTB over the span of TB treatment and is a part of the FACIT measurement system [8]. The development of the tool paved way to a more systematic evaluation of HRQOL among patients with TB.

Several studies have been carried-out regarding the HRQOL of TB patients around the world. A recent longitudinal multicentre study during the six-month standard TB treatment in South Africa reported that HRQOL of the study samples was impaired in all physical, mental and psycho-social health domains at treatment start. However, the HRQOL of the patients improved significantly and in a clinically meaningful manner during the course of standard TB treatment [9]. Another study conducted among 1034 patients with TB who were starting treatment under the Revised National Tuberculosis Control Programme (RNTCP) in a North Indian city indicated that the physical health, psychological health, social relationships and environmental domain were generally better among men, urban residents, younger patients, patients with higher socio-economic status and those with less severe disease [10]. Moreover, a systematic review which focused on the patient-reported HRQOL reported that although standard TB treatment improved all health domains, psychological well-being and social functioning remained impaired in microbiologically cured patients after treatment [11].

Despite the abundance of literature about this topic in other parts of the globe, there is a scaricity in published literature reporting HRQOL among TB patients in Saudi Arabia. Considering that $\mathrm{TB}$ is a serious public health problem in the country, it is paramount that evaluation of HRQOL among TB patients in the country should be conducted in a regular basis to form a body of knowledge about this topic in the country; thus, informing health policy makers and healthcare providers. This is also the first study to assess the HRQOL of TB patients in the country using an instrument that was specifically designed for such patients. Furthermore, the presence of patience from with different nationalities in the country calls of a regular evaluation of their quality of life to ensure that everyone receives due treatment and care, regardless of cultural or religious background. Therefore, this study was conducted to explore the multi-dimensional HRQOL among tuberculosis patients and examine any possible association between HRQOL components and the patients' demographic characteristics.

\section{Methods}

\subsection{Design}

This study utilized a descriptive, cross-sectional design.

\subsection{Setting and Sample}

The study was conducted among a convenience sample of 87 patients diagnosed with $\mathrm{TB}$ and who were receiving treatment in the National TB Control Program (NTP), Ministry of Health, Kingdom of Saudi Arabia.

\subsection{Instrument}

A standardized survey questionnaire with two parts was used to collect from the respondents. The first part was formulated by the researchers to collect data on the demographic characteristics of the respondents, which includes age, gender, nationality, marital status, education, residence, smoking status, employment status, duration of TB treatment, and whether they travelled outside the country in the last six months.

Part two was the Functional Assessment of Chronic Illness Therapy-Tuberculosis (FACIT-TB) by [12]. FACIT-TB is a disease-specific instrument designed to assess QOL in patients diagnosed with PTB and is a part of the FACIT measurement system. It comprises 45 items: 17 items covering physical well-being (possible score range 0-68), seven items covering social and economic well-being (possible score range 0-28), 11 items covering emotional well-being/living with TB (possible score range 0-44), seven items covering functional well-being (possible score range 0 
28), and three items covering spiritual well-being (possible score range 0-12). A 5-point Likert-type scale ranging from 0 (not at all) to 4 (very much) is assigned to each item. The FACIT-TB total score ranges from 0 to 180 , with a higher score corresponding to a better HRQOL. Using a classical psychometric approach, FACIT-TB has demonstrated excellent reliability, constructs validity, and is a sensitive instrument to set clinically significant differences in longitudinal studies of TB treatment. The internal consistency of the entire scale was 0.92 , whereas the Cronbach's alpha coefficients for the FACIT-TB subscales were uniformly high across all of the subscales, ranging from 0.81 to 0.93 . Item intra-class correlation coefficients for testre-test reliability analysis ranged from 0.72 to 0.92 [12].

\subsection{Data Collection}

Prior to data collection, the researchers coordinated with the nursing staffs and medical doctors of the patients to inform the patients to proceed to a designated room after their check-up. The researchers conducted a questionnaireguided interview to each patient (one researcher for one patient) in a room. The researchers read each questions two times before asking for the response from the patients. No additional questions were asked from the patients other than the questions in the questionnaire. The researchers recorded the response of the patients in the questionnaire right immediately. After the interview, the questionnaire was put in a white envelope and sealed in front of the patients. All sealed envelopes were collected by the principal investigator from each researcher at the end of each week for safe keeping in a locked cabinet. Data collection was done for 6 months from January-June 2017.

\subsection{Ethical Consideration}

The study was approved by the Institutional Review Board, General Directorate of Health Affairs, Ministry of Health, Madinah, Saudi Arabia. During the recruitment process, a thorough explanation of the purpose of the study, potential risks, and benefits of participation, as well as the expected participation, the rights, and the voluntary participation of the respondents. Adequate time was provided to the patients to ask questions or clarifications about the study. A written informed consent was secured from each respondent. During the interview, the information about the study was reiterated as well as the rights of the respondents. Privacy was provided during the interview. Data were secured in a locked cabinet. Permission to use the instrument was sought from the copyright holder of the tool. No incentive was provided for participation.

\subsection{Statistical Analysis}

All data analyses were conducted using the SPSS version 22.0. Descriptive statistics were used, accordingly, to fully describe the demographic characteristics of the respondents. Mean and standard deviation were computed to identify the HRQOL of the respondents. Independent sample t-test, One- way Analysis of Variance with post hoc Tukey HSD test, and Pearson product moment correlation were conducted to examine the association between the demographic characteristics and HRQOL of the respondents.

\section{Results}

Table 1 shows the profile of the respondents. The mean age of the respondents was $37.54(\mathrm{SD}=15.24)$ years. Almost half of the total number of respondents are Saudi (48.3\%) and lived in urban settings $(90.8 \%)$, whereas half of them are married. Approximately $31.0 \%$ had primary education, while $32.2 \%$ and $27.6 \%$ had secondary and tertiary education. Only $9.2 \%$ had no formal education. The majority of the respondents were employed (75.9\%). The respondents mostly don't smoke (78.2\%) and no history of travelling outside Saudi Arabia in the last 6 months (66.7\%). The minimum duration of disease since confirmed with tuberculosis is 1 month whereas the highest is 32 months. The mean duration of disease among the respondents is 5.04 months $(\mathrm{SD}=6.91)$.

Table 1. Demographic characteristics of the respondents $(n=87)$.

\begin{tabular}{llll}
\hline Variable & & Mean & SD \\
\hline Age & Years & 37.54 & 15.24 \\
Duration of TB ${ }^{\text {a }}$ treatment & Months & 5.04 & 6.91 \\
& & $\mathrm{n}$ & $\%$ \\
Gender & Female & 32 & 36.8 \\
& Male & 55 & 63.2 \\
Nationality & Non-Saudi & 45 & 51.7 \\
& Saudi & 42 & 48.3 \\
Marital status & Single & 40 & 46.0 \\
& Married & 44 & 50.6 \\
Education & Widdow/er & 3 & 3.4 \\
& Primary & 27 & 31.0 \\
& Secondary & 28 & 32.2 \\
Residence & College & 24 & 27.6 \\
Smoking status & No formal education & 8 & 9.2 \\
& Urban & 79 & 90.8 \\
Employment status & Rural & 8 & 9.2 \\
& Non-smoker & 68 & 78.2 \\
Travelled outside Saudi Arabia & No & 19 & 21.8 \\
in the last 6 months & Smoker & 21 & 24.1 \\
& Unemployed & 66 & 75.9 \\
\hline & Employed & 58 & 66.7 \\
& Yes & 29 & 33.3 \\
\hline
\end{tabular}

Note. ${ }^{\mathrm{a}}$ Tuberculosis

\subsection{Health-Related Quality of Life}

The overall HRQOL of the respondents was poor, with a mean score of 85.43 ( $\mathrm{SD}=24.97)$, possible scores ranging from 0 to 180 . The respondents' minimum score was 2.00 indicating a very poor HRQOL, while the maximum of 127.00 indicating a good HRQOL. Specifically, the physical well-being had a mean score of $21.29(\mathrm{SD}=12.25$, range $=$ 0.00 - 44.00); whereas social and economic well-being, emotional well-being/ stigma of having TB, functional wellbeing, and spiritual well-being had mean scores of 17.12 (SD $=6.33$, range $=0.00-26.00), 18.74(\mathrm{SD}=10.35$, range $=$ $0.00-39.00), 20.69(\mathrm{SD}=7.56$, range $=0.00-28.00)$, and 
$7.60(\mathrm{SD}=3.28$, range $=0.00-12.00)$.

\subsection{Association Between the Demographic Characteristics and the HRQOL}

The results of the association between the demographic characteristics and the different dimensions of the HRQOL were summarized in Tables 2 to 7 . As reflected, most of the demographic variables showed no statistical association with the dimensions of HRQOL. Only age, smoking status, duration of $\mathrm{TB}$, travelled outside KSA, and educational attainment exhibited significant association to some degree with some of the dimensions of HRQOL. Age had weak negative correlation with physical well-being $(r=-0.22, p$
$=.043$ ). Furthermore, patients who were non-smokers had better physical well-being $(t=2.38, p=.019)$, social and economic well-being $(t=2.59, p=.011)$ and functional wellbeing $(t=2.14, p=.035)$ than patients who smoke. Moreover, duration of TB showed a weak positive correlation with emotional well-being $(r=0.25, p=.019)$ and overall HRQOL $(r=0.23, p=.030)$. TB patients who had history of travelling outside KSA had poorer emotional well-being compared to those who did not have similar experience $(t=2.74, p=.007)$. Finally, patients who had no formal education had poorer functional well-being compared to those patients with primary education and secondary education.

Table 2. Association between demographic characteristics and physical well-being $(n=87)$.

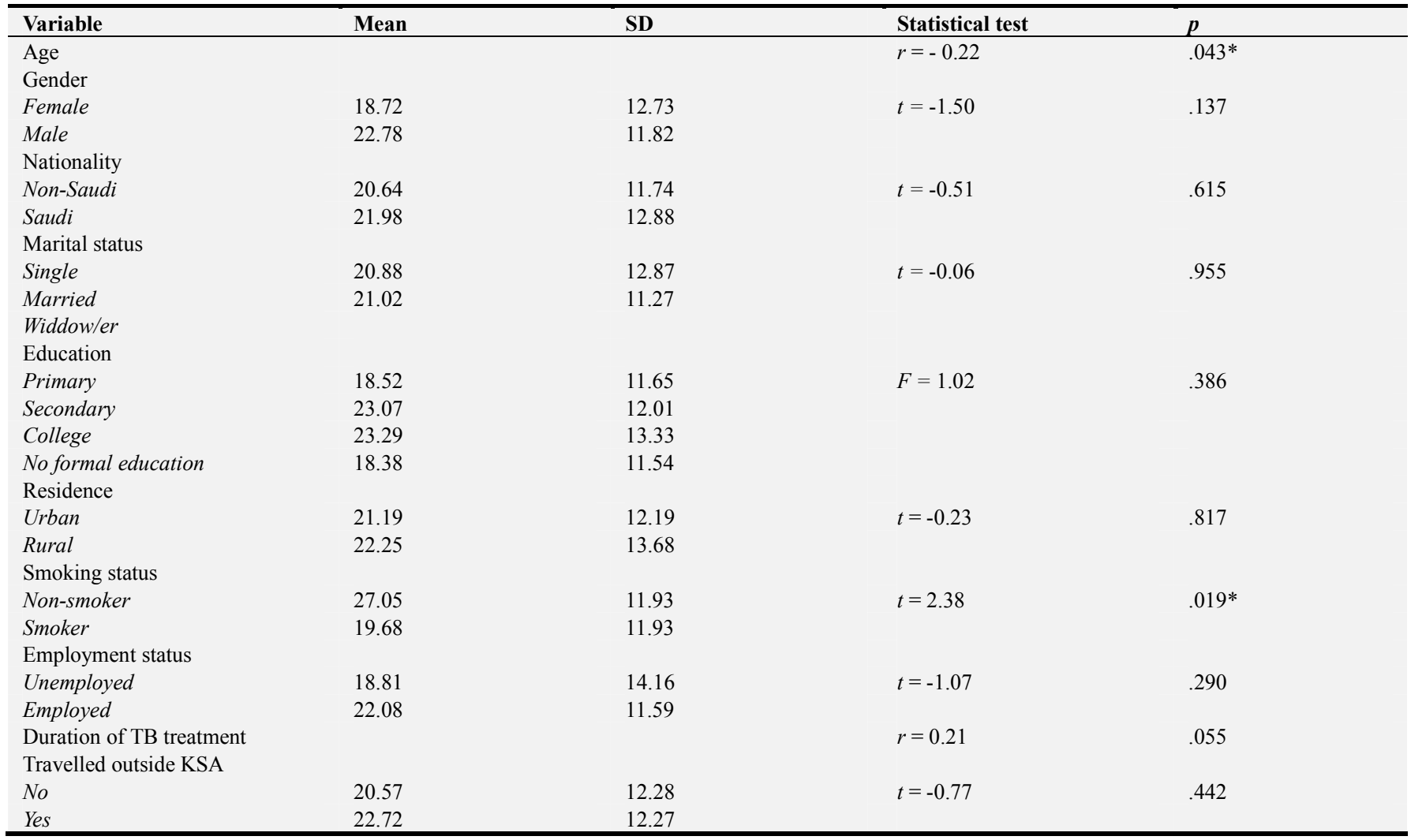

Table 3. Association between demographic characteristics and social and economic well-being $(n=87)$.

\begin{tabular}{|c|c|c|c|c|}
\hline Variable & Mean & SD & Statistical test & $p$ \\
\hline $\begin{array}{l}\text { Age } \\
\text { Gender }\end{array}$ & & & $r=0.18$ & .096 \\
\hline $\begin{array}{l}\text { Female } \\
\text { Male } \\
\text { Nationality }\end{array}$ & $\begin{array}{l}16.69 \\
17.36\end{array}$ & $\begin{array}{l}6.55 \\
6.24\end{array}$ & $t=-0.48$ & .634 \\
\hline $\begin{array}{l}\text { Non-Saudi } \\
\text { Saudi } \\
\text { Marital status }^{\text {a }}\end{array}$ & $\begin{array}{l}16.53 \\
17.74\end{array}$ & $\begin{array}{l}6.66 \\
5.97\end{array}$ & $t=-0.87$ & .387 \\
\hline $\begin{array}{l}\text { Single } \\
\text { Married } \\
\text { Education }\end{array}$ & $\begin{array}{l}16.53 \\
17.48\end{array}$ & $\begin{array}{l}6.77 \\
6.04\end{array}$ & $t=-0.68$ & .498 \\
\hline $\begin{array}{l}\text { Primary } \\
\text { Secondary } \\
\text { College } \\
\text { No formal education } \\
\text { Residence }\end{array}$ & $\begin{array}{l}17.74 \\
16.25 \\
16.67 \\
19.38\end{array}$ & $\begin{array}{l}5.49 \\
7.08 \\
7.24 \\
5.92\end{array}$ & $F=0.63$ & .595 \\
\hline
\end{tabular}




\begin{tabular}{lllll}
\hline Variable & Mean & SD & Statistical test & $p$ \\
\hline Urban & 16.97 & 6.53 & $t=-0.65$ & .519 \\
Rural & 18.50 & 3.85 & & $.011^{*}$ \\
Smoking status & & & $t=2.59$ & \\
Non-smoker & 18.01 & 5.77 & & .626 \\
Smoker & 13.89 & 7.32 & $t=-.049$ & .517 \\
Employment status & & & & \\
Unemployed & 16.52 & 7.45 & $r=0.07$ & .065 \\
Employed & 17.30 & 5.98 & $t=1.87$ & \\
Duration of TB treatment & & & \\
Travelled outside KSA & 18.00 & 5.95 & 6.78 & \\
No & 15.34 & & & \\
Yes & & & \\
\hline
\end{tabular}

Note. ${ }^{a}$ Widdow/er was excluded in the analysis.

*Significant at 0.05 level

Table 4. Association between demographic characteristics and emotional well-being $(n=87)$.

\begin{tabular}{|c|c|c|c|c|}
\hline Variable & Mean & SD & Statistical test & $p$ \\
\hline \multicolumn{4}{|l|}{ Gender } & .733 \\
\hline Female & 16.00 & 10.33 & $t=-1.91$ & .060 \\
\hline Male & 20.33 & 10.12 & & \\
\hline \multicolumn{5}{|l|}{ Nationality } \\
\hline Non-Saudi & 18.11 & 11.19 & $t=-0.58$ & .563 \\
\hline Saudi & 19.40 & 9.46 & & \\
\hline \multicolumn{5}{|l|}{ Marital status ${ }^{\mathrm{a}}$} \\
\hline Single & 18.35 & 11.04 & $t=-0.16$ & .878 \\
\hline Married & 18.70 & 9.98 & & \\
\hline \multicolumn{5}{|l|}{ Education } \\
\hline Primary & 20.93 & 12.03 & $F=2.48$ & .067 \\
\hline Secondary & 19.29 & 10.61 & & \\
\hline College & 14.25 & 7.03 & & \\
\hline No formal education & 22.88 & 8.63 & & \\
\hline \multicolumn{5}{|l|}{ Residence } \\
\hline Urban & 18.63 & 10.16 & $t=-0.29$ & .773 \\
\hline Rural & 19.75 & 12.90 & & \\
\hline \multicolumn{5}{|l|}{ Smoking status } \\
\hline Non-smoker & 18.15 & 10.66 & $t=-1.00$ & .319 \\
\hline Smoker & 20.84 & 9.10 & & \\
\hline \multicolumn{5}{|l|}{ Employment status } \\
\hline Unemployed & 20.14 & 11.39 & $t=0.71$ & .478 \\
\hline Employed & 18.29 & 10.05 & & \\
\hline Duration of TB treatment & & & $r=0.25$ & $.019^{*}$ \\
\hline Travelled outside KSA & & & & \\
\hline No & 20.81 & 10.82 & $t=2.74$ & $.007 * *$ \\
\hline Yes & 14.59 & 8.00 & & \\
\hline
\end{tabular}

Note. ${ }^{a}$ Widdow/er was excluded in the analysis.

*Significant at 0.05 level, ** Significant at 0.01 level

Table 5. Association between demographic characteristics and functional well-being $(n=87)$.

\begin{tabular}{|c|c|c|c|c|}
\hline Variable & Mean & SD & Statistical test & $p$ \\
\hline Age & & & $r=0.03$ & .760 \\
\hline \multicolumn{5}{|l|}{ Gender } \\
\hline Female & 20.50 & 8.44 & $t=-0.18$ & .860 \\
\hline Male & 20.80 & 7.07 & & \\
\hline \multicolumn{5}{|l|}{ Nationality } \\
\hline Non-Saudi & 20.42 & 8.12 & $t=-0.34$ & .735 \\
\hline Saudi & 20.98 & 6.99 & & \\
\hline \multicolumn{5}{|c|}{ Marital status $\mathrm{s}^{\mathrm{a}}$} \\
\hline Single & 20.35 & 7.72 & $t=-0.55$ & .582 \\
\hline Married & 21.25 & 7.20 & & \\
\hline \multicolumn{5}{|l|}{ Education } \\
\hline Primary & 22.85 & 6.60 & $F=3.72$ & $.015^{*}$ \\
\hline Secondary & 25.50 & 6.51 & & \\
\hline College & 20.25 & 8.34 & & \\
\hline
\end{tabular}




\begin{tabular}{|c|c|c|c|c|}
\hline Variable & Mean & SD & Statistical test & $p$ \\
\hline $\begin{array}{l}\text { No formal education } \\
\text { Residence }\end{array}$ & 17.61 & 7.59 & & \\
\hline Urban & 20.62 & 7.71 & $t=-0.27$ & .790 \\
\hline $\begin{array}{l}\text { Rural } \\
\text { Smoking status }\end{array}$ & 21.38 & 6.26 & & \\
\hline Non-smoker & 21.59 & 7.59 & $t=2.14$ & $.035^{*}$ \\
\hline $\begin{array}{l}\text { Smoker } \\
\text { Employment status }\end{array}$ & 17.47 & 6.66 & & \\
\hline Unemployed & 20.86 & 7.55 & $t=0.12$ & .908 \\
\hline Employed & 20.64 & 7.62 & & \\
\hline $\begin{array}{l}\text { Duration of TB treatment } \\
\text { Travelled outside KSA }\end{array}$ & & & $r=0.01$ & .923 \\
\hline $\mathrm{No}$ & 20.72 & 7.28 & $t=-0.06$ & .952 \\
\hline Yes & 20.62 & 8.22 & & \\
\hline
\end{tabular}

Note. ${ }^{a}$ Widdow/er was excluded in the analysis.

*Significant at 0.05 level

Table 6. Association between demographic characteristics and spiritual well-being $(n=87)$.

\begin{tabular}{|c|c|c|c|c|}
\hline Variable & Mean & SD & Statistical test & $p$ \\
\hline Age & & & $r=0.06$ & .595 \\
\hline \multicolumn{5}{|l|}{ Gender } \\
\hline Female & 7.31 & 3.91 & $t=-0.57$ & .572 \\
\hline Male & 7.76 & 2.89 & & \\
\hline \multicolumn{5}{|l|}{ Nationality } \\
\hline Non-Saudi & 7.47 & 3.49 & $t=-0.38$ & .702 \\
\hline Saudi & 7.74 & 3.08 & & \\
\hline \multicolumn{5}{|l|}{ Marital status $\mathrm{s}^{\mathrm{a}}$} \\
\hline Single & 7.43 & 3.30 & $t=-0.45$ & .655 \\
\hline Married & 7.75 & 3.33 & & \\
\hline \multicolumn{5}{|l|}{ Education } \\
\hline Primary & 8.33 & 2.60 & $F=1.10$ & .355 \\
\hline Secondary & 6.82 & 3.78 & & \\
\hline College & 7.46 & 3.73 & & \\
\hline No formal education & 8.25 & 2.16 & & \\
\hline \multicolumn{5}{|l|}{ Residence } \\
\hline Urban & 7.42 & 3.35 & $t=-1.62$ & .109 \\
\hline Rural & 9.38 & 2.92 & & \\
\hline \multicolumn{5}{|l|}{ Smoking status } \\
\hline Non-smoker & 7.76 & 3.11 & $t=0.90$ & .372 \\
\hline Smoker & 7.00 & 3.87 & & \\
\hline \multicolumn{5}{|l|}{ Employment status } \\
\hline Unemployed & 6.86 & 3.76 & $t=-1.19$ & .237 \\
\hline Employed & 7.83 & 3.11 & & \\
\hline Duration of TB treatment & & & $r=0.05$ & .639 \\
\hline \multicolumn{5}{|l|}{ Travelled outside KSA } \\
\hline No & 7.93 & 2.70 & $t=1.17$ & .249 \\
\hline Yes & 6.93 & 4.19 & & \\
\hline
\end{tabular}

Note. ${ }^{a}$ Widdow/er was excluded in the analysis.

Table 7. Association between demographic characteristics and overall health-related quality of life $(n=87)$.

\begin{tabular}{lllll}
\hline Variable & Mean & SD & Statistical test & $p$ \\
\hline Age & & & $r=0.19$ & .086 \\
Gender & & & $t=-1.79$ & .077 \\
Female & 79.212 & 26.39 & & \\
Male & 89.04 & 23.60 & $t=-0.87$ & .388 \\
Nationality & & & \\
Non-Saudi & 83.18 & 26.32 & $t=-0.49$ & .627 \\
Saudi & 87.83 & 23.50 & & \\
Marital status & & & \\
Single & 83.53 & 28.13 & & \\
Married & 86.20 & 21.38 & $F 52$ \\
Education & & & \\
Primary & 88.37 & 25.98 & & \\
Secondary & 83.04 & 23.89 & & \\
\hline
\end{tabular}




\begin{tabular}{|c|c|c|c|c|}
\hline Variable & Mean & SD & Statistical test & $p$ \\
\hline College & 81.92 & 27.55 & & \\
\hline No formal education & 94.38 & 23.33 & & \\
\hline \multicolumn{5}{|l|}{ Residence } \\
\hline Urban & 84.84 & 25.71 & $t=-0.69$ & .492 \\
\hline Rural & 91.25 & 15.84 & & \\
\hline \multicolumn{5}{|l|}{ Smoking status } \\
\hline Non-smoker & 85.19 & 25.27 & $t=-0.17$ & .870 \\
\hline Smoker & 86.26 & 24.49 & & \\
\hline \multicolumn{5}{|l|}{ Employment status } \\
\hline Unemployed & 83.19 & 30.96 & $t=-0.47$ & .640 \\
\hline Employed & 86.14 & 22.97 & & \\
\hline $\begin{array}{l}\text { Duration of TB treatment } \\
\text { Travelled outside KSA }\end{array}$ & & & $r=0.23$ & $.030^{*}$ \\
\hline No & 88.03 & 24.48 & $t=1.39$ & .169 \\
\hline Yes & 80.21 & 25.54 & & \\
\hline
\end{tabular}

Note. ${ }^{a}$ Widdow/er was excluded in the analysis.

*Significant at 0.05 level

\section{Discussion}

This study determined the multidimensional quality of life (QOL) among tuberculosis patients and its relationship with their demographic profiles of the respondents. The strategy of evaluating the QOL in TB patients is an important outcome to measure the efficacy of new treatments or interventions geared towards eliminating the burden associated with the disease. Two significant finding are discussed in this section.

First, the result of the study showed a poor overall HRQOL among TB patients and a poor to moderate range on the different dimensions of HRQOL. This result adds to the existing evidence which have documented and reported impairment in the quality of life among tuberculosis patients with significant deficits in physical, as well as psychological components $[5,13]$. The findings of the study therefore conformed to other studies that physical aspect of tuberculosis patients influences their quality life [2, 14] However, the present findings revealed that the HRQOL of the TB patient in Saudi Arabia were lower compared to previous study using the same tool in Iraq [8]. Several factors were identified in the literature that may influence the HRQOL of this population, such as exposure to secondhand smoke, unemployment, having lower educational attainment, numbers of symptoms and drug reactions, low perceived social support, lower body mass index, and having positive sputum smear result [13]. The findings also imply that the respondents perceived their physical well-being and emotional well-being poorly, while social and economical well-being, functional well-being and spiritual well-being were perceived moderately. These findings suggest a potential role for targeted, culturally relevant physical and multidimensional interventions for persons with TB disease to improve all the dimensions of their HRQOL.

Second, age, smoking status, duration of $\mathrm{TB}$, travelled outside KSA, and educational attainment exhibited significant some degree of association with some of the dimensions of HRQOL. It was found that aging had negative effect on the TB patients' physical well-being, with the younger patients having better physical well-being status than older patients. This result is congruent with other studies which published correlations between the quality of life among TB patients and demographic factors [10, 13, 15-17]. In addition, this could be explicated based on the overall health status among individuals in older age group and possible existing co-morbidities among older population where illnesses such as hypertension and diabetes are more prominent. The influence of co-morbidities, however, was not examined in this study; hence, should be investigated in future studies.

Furthermore, patients who were non-smokers exhibited better physical well=being, social and economical well-being and functional well-being. This finding is similar with previous studies conducted in Iran [18] and Malaysia [19]. The unfavorable impact of cigarette smoking on health is well-known. It is also one of the risk-factors for tuberculosis, and patients with TB are strongly advised to stop smoking to improve their health. Also, cigarette smoking can cause impaired social function because of a negative perception of others to cigarette smoking and the perceived harmful effects to health [18]. Also, the prices of cigarettes in the country had doubled, which may contribute to additional financial burdens for the patients. These may explain the current findings of the study.

A significant correlation was also found between the duration of the tuberculosis since the respondents were confirmed of having the disease and their emotional wellbeing and overall HRQOL. Tuberculosis is a disease with social implications due to the stigma attached to it which is evident from the poorer emotional mean scores among respondents diagnosed of tuberculosis for a longer time period compared to respondents just recently diagnosed. This finding could be explained by Dias et al. [16] who provided insight into the experiences of those with TB and illuminate causes of reduced quality of life which demonstrated significant levels of anxiety and stigmatization. The stigmatization, which negatively impacts the emotional wellbeing of TB patients, is heightened by inaccurate beliefs concerning the etiology and transmissibility of TB. The 
experience of travelling outside Saudi Arabia was also found to have negative effect on the emotional well-being of the patients. Specifically, patients who had experienced travelling outside the country had poorer emotional wellbeing compared to those without similar experience. This may be associated with the number of expatriates in the sample, who often travel to their own country to be with their family. Detachment from love ones is an emotional struggle which individuals working away from their family and friends often experience. As can be gleaned in Table 2 to 7 , non-Saudi patients exhibited poorer HRQOL in all dimensions, although insignificant, with Saudi nationals.

The educational attainment of the respondents also played a pivotal role in the functional well-being among respondents. Those having no formal education displayed poorer functional well-being compared to those with higher level of educational attainment. This finding could be explained and supported by others reports [14] that stated that people who are well-educated have the tendency to have better financial status and comprehend better about the disease process and its treatment, thus adapt better and individuals with higher income may have better ways of life.

There are few limitations in this study that may have some potential impacts on the results. All prognostic features such as co-morbidities were not included in the analysis. The study used a convenience sample; therefore, the findings may not be generalizable to all TB patients in Saudi Arabia. Furthermore, the study did not explore the differences in quality of life among patients in specific groups like latent $T B$, extrapulmonary $\mathrm{TB}$, multi-drug resistant and those associated with infections like Human Immunodeficiency Virus (HIV).

\section{Conclusion}

The study reported poor HRQOL among patients with TB in Saudi Arabia. The results also affirm the findings of other existing data that some demographic qualities and physical attributes of the individual affect the overall HRQOL as well as the different HRQOL dimensions among patients with TB. Strategies to strengthen the treatment support could sustain acceptable levels of physical, social and emotional functioning among TB patients. The need to increase public awareness about tuberculosis is needed to ensure prompt healthcare seeking, early detection, adherence to remedy, and better prognosis. Furthermore, a multidimensional and holistic management of TB in Saudi Arabia is proposed in order to enhance all the dimensions of HRQOL of TB patients.

\section{Declaration of Conflict of Interest}

The authors declare no conflict of interest.

\section{References}

[1] World Health Organization. (2017, March). Tuberculosis (TB). Retrieved October 13, 2017, from http://www.who.int/mediacentre/factsheets/fs 104/en/.
[2] Dhuria, M., Sharma, N., \& Ingle, G. K. (2008). Impact of tuberculosis on the quality of life. Indian journal of community medicine: official publication of Indian Association of Preventive \& Social Medicine, 33 (1), 58.

[3] Mamani, M., Majzoobi, M. M., Ghahfarokhi, S. M., EsnaAshari, F., \& Keramat, F. (2014). Assessment of health-related quality of life among patients with tuberculosis in Hamadan, Western Iran. Oman Medical Journal, 29 (2), 102.

[4] Al-Orainey, I., Alhedaithy, M. A., Alanazi, A. R., Barry, M. A., \& Almajid, F. M. (2013). Tuberculosis incidence trends in Saudi Arabia over 20 years: 1991-2010. Annals of Thoracic Medicine, 8 (3), 148.

[5] Brown, J., Capocci, S., Smith, C., Morris, S., Abubakar, I., \& Lipman, M. (2015). Health status and quality of life in tuberculosis. International Journal of Infectious Diseases, 32, 68-75.

[6] The WHOQOL Group. (1998). Development of the World Health Organization WHOQOL-BREF quality of life assessment. Psychological Medicine, 28 (3), 551-558.

[7] McKenna, S. P. (2011). Measuring patient-reported outcomes: moving beyond misplaced common sense to hard science. BMC Medicine, 9 (1), 86.

[8] Dujaili, J. A., Blebil, A. Q., Awaisu, A., Bredle, J., Dujaili, M. A., Hassali, M. A., \& Sulaiman, S. S. (2013). Development of a multi-dimensional health related quality of life measure specific for pulmonary tuberculosis patients in Iraq. Value in Health, 16 (3), A95-A96.

[9] Kastien-Hilka, T., Rosenkranz, B., Sinanovic, E., Bennett, B., \& Schwenkglenks, M. (2017). Health-related quality of life in South African patients with pulmonary tuberculosis. PloS One, 12 (4), $\mathrm{e} 0174605$.

[10] Aggarwal, A. N., Gupta, D., Janmeja, A. K., \& Jindal, S. K. (2013). Assessment of health-related quality of life in patients with pulmonary tuberculosis under programme conditions. The International Journal of Tuberculosis and Lung Disease, 17 (7), 947-953.

[11] Kastien-Hilka, T., Abulfathi, A., Rosenkranz, B., Bennett, B., Schwenkglenks, M., \& Sinanovic, E. (2016). Health-related quality of life and its association with medication adherence in active pulmonary tuberculosis-a systematic review of global literature with focus on South Africa. Health and Quality of Life Outcomes, 14 (1), 42.

[12] Abdulelah, J., Sulaiman, S. A. S., Hassali, M. A., Blebil, A. Q., Awaisu, A., \& Bredle, J. M. (2015). Development and psychometric properties of a tuberculosis-specific multidimensional health-related quality-of-life measure for patients with pulmonary tuberculosis. Value in Health Regional Issues, 6, 53-59.

[13] Masumoto, S., Yamamoto, T., Ohkado, A., Yoshimatsu, S., Querri, A. G., \& Kamiya, Y. (2014). Factors associated with health-related quality of life among pulmonary tuberculosis patients in Manila, the Philippines. Quality of Life Research, 23 (5), 1523-1533.

[14] Kisaka, S. M., Rutebemberwa, E., Kasasa, S., Ocen, F., \& Nankya-Mutyoba, J. (2016). Does health-related quality of life among adults with pulmonary tuberculosis improve across the treatment period? A hospital-based cross sectional study in Mbale Region, Eastern Uganda. BMC Research Notes, 9 (1), 467. 
[15] Adeyeye, O. O., Ogunleye, O. O., Coker, A., Kuyinu, Y., Bamisile, R. T., Ekrikpo, U., \& Onadeko, B. (2014). Factors influencing quality of life and predictors of low quality of life scores in patients on treatment for pulmonary tuberculosis: a cross sectional study. Journal of Public Health in Africa, 5 (2), 366. doi: 10.4081/jphia.2014.366.

[16] Dias, A. A. L., de Oliveira, D. M. F., Turato, E. R., \& de Figueiredo, R. M. (2013). Life experiences of patients who have completed tuberculosis treatment: a qualitative investigation in southeast Brazil. BMC Public Health, 13 (1), 595.

[17] Louw, J., Peltzer, K., Naidoo, P., Matseke, G., Mchunu, G., \& Tutshana, B. (2012). Quality of life among tuberculosis (TB),
TB retreatment and/or TB-HIV co-infected primary public health care patients in three districts in South Africa. Health and Quality of Life Outcomes, 10 (1), 77.

[18] Darvishpoor Kakhki, A., \& Masjedi, M. R. (2015). Factors associated with health-related quality of life in tuberculosis patients referred to the National Research Institute of Tuberculosis and Lung Disease in Tehran. Tuberculosis and Respiratory Diseases, 78 (4), 309-314.

[19] Atif, M., Sulaiman, S. A. S., Shafie, A. A., Asif, M., Sarfraz, M. K., \& Low, H. C. (2014). Impact of tuberculosis treatment on health-related quality of life of pulmonary tuberculosis patients: a follow-up study. Health and Quality of Life Outcomes, 12 (1), 19. 